\title{
Computer simulation on composition of curricular components of an academic process
}

\author{
Patrícia F.Amorim $^{a}$, Leila Andrade ${ }^{a}$ and Leonardo Lima \\ ${ }^{a}$ School of Applied Informatics - Federal University of Rio de Janeiro (UNIRIO) \\ Av. Pasteur 458, Térreo, Urca-22290-240 - Rio de Janeiro-RJ-Brasil \\ ${ }^{b}$ Centro Federal de Educação Tecnológica - CEFET-RJ \\ Av. Maracanã, 229-Maracanã - 20271-110 - Rio de Janeiro - RJ-Brasil \\ Email: patricia.amorim@uniriotec.br
}

\begin{abstract}
This study proposes a methodology to develop a mathematical model that may help university students choose the best composition of curriculum components. The aim is to provide support for students' decisions in the disciplines registration process, and hence reduce the time needed in order to complete their course. This paper examines the Federal University of Rio de Janeiro (UNIRIO) Information Systems (IS) Master of Science (MSc) students' composition of curricular components, and is based on past UNIRIO IS graduates who could not finish the course within the given time frame as defined in the pedagogical project.
\end{abstract}

Within the School of Applied Informatics (SAI) there is a tutor whose duty is to guide students in their academic life by helping them choose appropriate curriculum components. Students with complicated academic backgrounds pose great difficulty for the tutors. Therefore, SAI finds there is a need to improve and increase the efficiency of the enrolment process into appropriate curricular components.

This paper can be divided into two phases; the first provides a literature review that integrates business process modeling, and simulation to business management and the foundation of mathematical models. Initially, we consider the Markov model that is a state transition model. Thus, the evolution of a process in the future is conditioned on the present and past, and is only dependent on its present value. These models have become useful in decision analysis when a problem involves evolution over the time, and when an event can occur repeatedly in an analysed period of time. The second phase of this paper presents a case study using the SAI curriculum. The current semester is analysed, in order to refute or affirm the observations obtained in the previous phase. Quantitative variables will be determined in subscribe (prospective) students in disciplines process in order to collect data for these variables to create subsidies for the Markov model.

Once the statistical analysis of the data has been completed, we intend simulate scenarios for final analysis. After the simulations are finished, the scenario analysis will allow the tutor to handle the options for students and offer the best composition of curriculum components. Thereafter, this paper intends to offer a model optimized for the mentoring of students in the SAI.

Keywords: Business Process Modeling, Process Simulation, Process Simulation Tools, Mathematical Models for Process Simulation. 


\section{INTRODUCTION}

We propose the use of process simulation to define a model that helps students choose the best composition of curricular components, which minimizes the time spent by a student in an educational institution. Therefore, the purpose of this model is to guide students in the School of Applied Informatics (SAI) at UNIRIO in choosing appropriate curricular components so that they finish their course within the defined period of time so that the students can join the labour market as soon as possible. SAI has reported that inflexible timetables, reprobation in curricular components which are prerequisites from other components may cause difficulty in academic life.

"In summary, a process model represents and explains, in simplified form, the reality of the structure of activities and resources that enable the organization to function." [Paim, 2009]. "Without worrying about a precise definition of simulation, we can understand it as the use of models for the study of real problems of a complex nature, through computational experimentation. Thus, the simulation is the process of building a model that replicates the functioning of a real or idealized (yet to be built!) And conduct computational experiments with this model in order to understand better the problem under study, test different alternatives for its operation and to propose better ways to operate it. "[Saliby, 1999].

Theoretical studies have helped find applications of process modeling such as the cost management in the process of registration and enrollment at the University of Cruz Alta, located in the state of Rio Grande do Sul [Mareth, 2009], the flow patients' simulation of the emergency of University Hospital Antonio Pedro, located in the city of Niteroi, in Rio de Janeiro [Souza, 2007], and the use of simulation in computer networks as in Barradas [2010] which uses mathematical modeling techniques and simulation optimization. These studies all use the association of process models and computer simulation.

We theorize that if a mathematical model, which represents the curriculum of pedagogical educational institutions, could be identified; the composition of curriculum components assisting in shortening the duration of the course could be predicted.

\section{PROCESS MODELS}

They can also be defined as a set of views that represent aspects of a business, allowing for the understanding of the reality of an organization, serving for communication and discussion of activities improvements [Magalhães, 2007].

These activities are well characterized share of the work carried out at one point by roles, according to a defined set of rules that establish the order and the conditions under which activities should be executed." [Engiel, 2009].

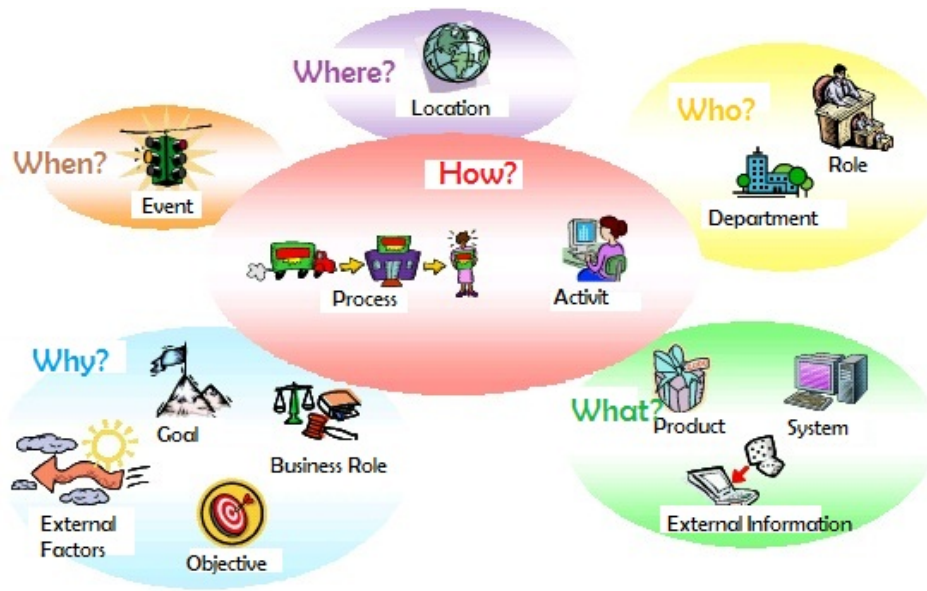

Figure 1. Meta- Model of Business Process [Magalhães, 2007].

To identify all activities involved in a business process, it is necessary to adopt a methodology to derive the requirements from the model developed and understand the processes' adaptation [Engiel, 2009], the diagram generated from the methodological approach of Sharp and Dermontt is described in Figure 2. 


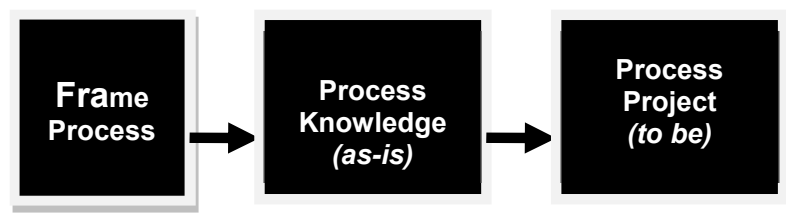

Figure 2. Approach to Business Process Modeling [Engiel, 2009].

Each item in the diagram corresponds to a phase of the methodology to process modeling. Therefore, Frame Process corresponds to the first phase, a survey of initial data, defining the scope and context of the business activities involved in the processes [Engiel, 2009]. The second phase, understanding the process "as is" (asis), is the evaluation of the achievement of the process objectives. This requires modeling the process from the documentation prepared in the previous phase, identifying what should be modeled and who is involved in the process [Engiel, 2009]. The third phase, Process Project (to-be), involves the elicitation of business requirements; determining improvements for a new type of process, analysis of the quality of information flow, identifying potential bottlenecks of the process [Engiel, 2009].

In the first phase of this paper, the definition of the scope of performance and process boundaries were held jointly with the director of SAI, based on modeling processes developed in the work of completing the undergraduate course of SAI [Engiel, 2009]. The process Subscribe Discipline, which is part of the academic macro-process is shown in Figure 3.

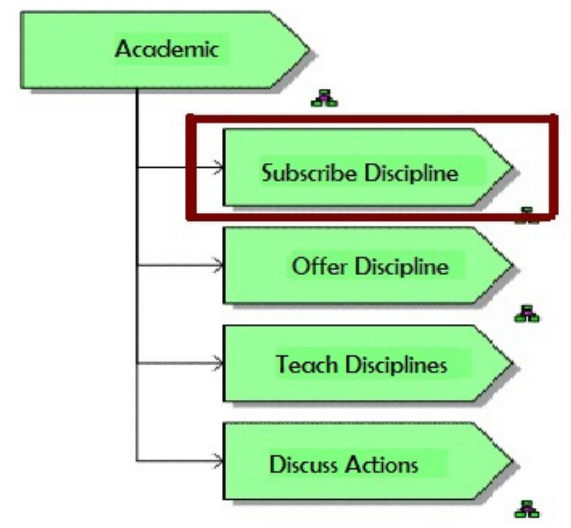

Figure 3. Academic Macro Process [Engiel, 2009].

\section{THE PROCESS CONTEXT DISCIPLINES SUBSCRIBING [Engiel, 2009]}

This process is responsible for registering students in curricular components, which is subdivided into: Enroll new students in disciplines, and Enroll veterans in discipline. The model process is shown in Figure 4:

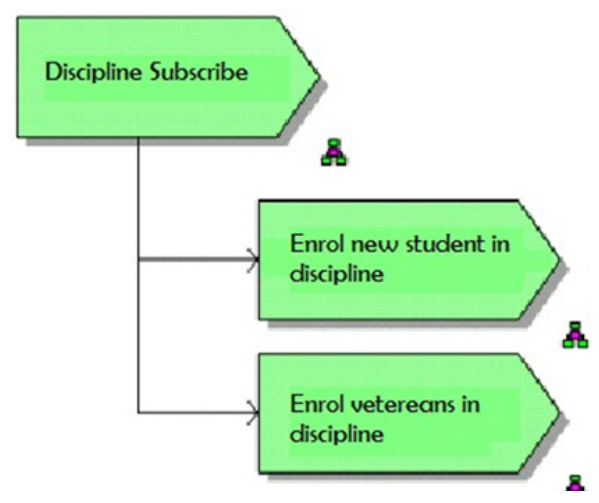

Figure 4. Subscribe to Process Disciplines [Engiel, 2009]. 


\subsection{Enroll new students in discipline}

The entry of a new student is made by themselves, in the effective registration with the Bureau of the University, which falls in the curricular components of the first period of the graduate course in IS [Engiel, 2009].

\subsection{Enroll veterans in discipline}

"The goal of this process is to allow the veteran student enroll in courses for the new school year with the help of their tutor. The process begins when the portal is released and the student's enrollment period in disciplines is initiated. The student accesses the portal and requests the student enrolls in the courses that they want. In the Student Portal, the veteran has access to a list of the disciplines of his course, mandatory and optional, not yet studied, and also has access to a listing of all the elective courses offered at the University without restrictions. At the end of the subscription request in disciplines period, the SAI system criticizes the subscription requests based initially on the consistency of preconditions and the compatibility of working hours. Then, if there are excessive requests for subscriptions, according to the maximum expected quantity of vacancies, the system prioritizes the following entry criteria of priority. The criteria are generally the following (in order of importance): "course in the student's home" (priority for students of the course which offered the discipline), "the prospect of payment in the period" (who has remaining hours to be held in the period, have priority), "student in the correct period of the discipline offered in the educational project." The solution offered by the SAI in filling vacancies of pupils entitled to registration usually does not end the matter, since the system cannot model all the possible exceptions of treatment (a course being offered at any time, with no prospect of graduating students only the next period and discipline offered annually, etc.). The director then tells the Information Technology Department that the school report registration application is available. Following this, the director shares the availability of the report enrollment request to the secretary. In turn, the secretary sends the tutor the registration request report and transcripts of the student. The tutor schedules the week of registration confirmation. At the end of the registration confirmation period, the student and tutor will check the report subscription request to decide whether to include and / or exclude disciplines from the enrollment request report. If it is necessary to make changes to the registration request, the tutor points out the mandatory report. For the academic guidance of the tutor, if there is the student's consense, in relation to suggestions for inclusion or exclusion of courses, the suggestions should be acknowledged in the report. If the student does not agree, it is recommended that the tutor marks on the back that the suggestion was not accepted by the student, in order to characterize the orientation was performed, but was not accepted. Two copies of the report must be signed, one for the tutor and another for the student. One copy stays with students for proof of their registration confirmation, and the second is sent to the school office. The secretary then verifies the changes in the registration request report. If there are changes in the registration request report, the secretary registers the changes in the SAI. If there's no changes or the necessary modifications are made, she confirms enrollment in SAI. Finally, the secretary files the registration application report. At the end of the process, students will be enrolled in senior courses. "[ Engiel, 2009].

\section{COMPUTER SIMULATION}

Historically, the simulation had its origin from the Monte Carlo method, which solved analytical mathematical problems, which solutions were not viable. It occurred during the 2nd World War [Mareth, 2009]. It was in the 1950s that the computer simulation began to be used in the United States aerospace industry. In the 1960s came the first industries applications, which occurred slowly because of the low power of computation at the time [Torres, 2006]. According to Saliby [1999], "the simulation is the process of building a model that replicates a real or idealized functioning (yet to be built!), and computational experiments conduct with this model, have the objective to understand better the problem under study, test different alternatives for its operation and propose better ways to operate it."

While the use of personal computers increases, and improvements in simulation software has helped the growing application simulation in the logistics and operational organizations, the advantages and disadvantages must be considered. The advantages and disadvantages of using simulation to solve problems are listed by Torres [2006]:

- Promotes creative solution: intuitive solutions can be modeled and tested quantitatively;

- Identifies problems: through the trials of the system interactions, identify causes of restrictions;

- You can predict results, analyzing projects and systems that still exists, exploring possibilities of new policies, procedures and management methods;

- Considers change of systems: to analyze the changes in real systems, statistically based and scientifically; 
- Promotes total solutions: allows that all instances of a problem could be simultaneously analyzed, requiring the participation of all involved in the areas. Even the less likely hypotheses can be tested and validated, so the solution generated is built by consensus;

- It may be economically efficient: the ability to evaluate alternatives allows a quick calculation of the impacts of new strategies and investments that may be needed to the solution proposed;

- Prepares the organization for change: people can be trained and organized in their way of working. The training of people can be a disadvantage if expertise and experience is needed, it may require significant time and investment for the organization, that is not always available;

- Promotes agility, allowing realizing systems analysis in long periods of operation in a short space of time. However, such analysis may be difficult to interpret because of the randomness, which can become a disadvantage;

- Increases knowledge: develops an understanding based on the experience of how the system functions;

- Checks solutions generated by other methods. If we use the simulation inappropriately, simple solutions could solve the same problem in less time and cost, and

- It may be simple: the constructed model can be used several times to perform an analysis, obtaining data easily. But if in some cases the model takes longer and cost more to be applied, it becomes a disadvantage.

The main advantage found for this research is the strategic capacity of prediction, using the process simulation application in curricular components, allows working hypotheses that anticipates the facts; it allows too, the adaptation of the student's profile curricular.

According to Saliby [1999], steps in the practical simulation application require:

- Construction of a conceptual model: fundamental in the simulation. This phase includes understanding and defining of the problem scope under study and what are its main objectives to be achieved and which model should respond to the decision makers. It can be logic, graphics, or even copious notes;

- Transforming the conceptual model into a computational model that allows testing it: set of actions laborious simulation process. The data collection perform occurs in this stage, and also the statistical analysis, programming, using an appropriate software, the verification and validation, and

- Experimental test of choice for analysis and alternative solutions: this phase is to test different alternatives, using the representation of the real system, which is the model simulation, sensitivity analysis to evaluate the effect of possible changes before they happen.

These three steps can be seen in Figure 5 .

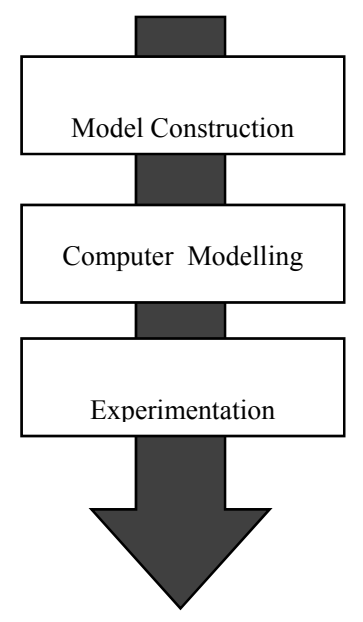

Figure 5. Steps of a Process Simulation [Saliby, 1999].

Based on in Figure 2, and the whole simulation theory studied until now, the simulation can be introduced into Business Process Modeling. 


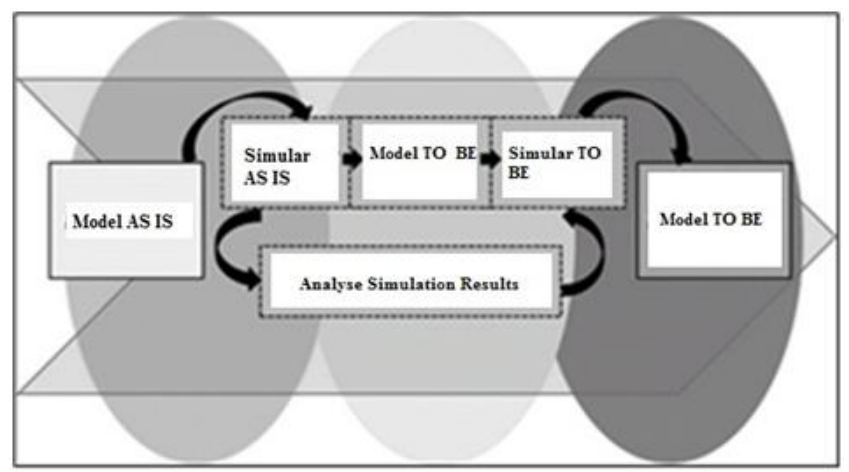

Figure 6. Simulation Modeling inserted into the Business Process [Paim, 1999].

These results can help the organization in their strategic planning decision.

The computer simulation is a tool that assists the analysis of flows of the curricular components and its bottlenecks, and identifying curricular components that have problems with queues and waiting. It also provides changes to the composition of the matrix of curricular course components and analyses the impacts of this change. Using an appropriate simulation application, we can identify the existence of a mathematical model that minimizes the time spent by a student at an educational institution.

\section{TECHNICAL TRAINING AND RESOURCE COMPUTER REQUIRED}

From Saliby [1999] a simulation research project requires technical skills such as good knowledge in statistical analysis techniques and process modeling. In regard of computational resources, the machines available nowadays are capable of processing complex applications. So the software has become a crucial factor in the use of simulation, because through them, complex problems can be processed by saving time and accuracy of the information. Table 1 shows the main software and its suppliers.

For this study, the chosen software is ARENA, which has a version of Training / Evaluation Mode (STUDENT) Academic, that provides all functionality to create and run simulation models.

Table 1. List of major simulation software [Saliby, 1999]

\begin{tabular}{|l|l|l|}
\hline \multicolumn{1}{|c|}{ PRODUTO } & \multicolumn{1}{|c|}{ EMPRESA } & HOME PAGE \\
\hline ARENA & Systems Modeling Corporation & www.sm.com \\
\hline AutoMod & Autosimulations & \\
\hline Extend & Imagine That & www.autosim.com \\
\hline GPSS H & Wolverine Software & www.imaginethatinc.com \\
\hline Micro Saint & Micro Analysis \& Design & www.madboulder.com \\
\hline ProModel & ProModel Corporation & www.promodel.com \\
\hline SIMPLE ++ & AESOP (Alemanha) & www.aesop.de \\
\hline $\begin{array}{l}\text { Simscrip II.5 e } \\
\text { MODSIM III }\end{array}$ & CACI Productos & www.caciasl.com \\
\hline TAYLOR II b & F\&H Simulations (Holanda) & www.taylorii.com \\
\hline VisSIM & Visual Solutions & www.vissim.com \\
\hline
\end{tabular}




\section{CONSIDERATIONS AND CONTINUING RESEARCH}

In this context, to improve simulation learning, it is required to observe the tutor's guide period in SAI to describe this process formally and investigate the quantitative variables that will make the Markov probability table. It is noticed that it also needs an investment in studies of quantitative models to support decision-making process, among simulation optimization techniques, which is cited in Barradas [2010].

This paper can be divided into two phases; the first provides a literature review that integrates business process modeling, simulation to business management and the foundation of mathematical models, the simulation and modeling of academic processes using mathematical models, and research tools which involved choosing the software ARENA. Initially, according to Silva [2006], the Markov model is a state transition model, in which the evolution of a process in the future, conditioning on the present and past, only depends on its present value. These models have become useful in decision analysis when a problem involves the evolution over the time and when the event can occur repeatedly in an analysed period of time.

The second phase of this paper presents a case study using the SAI curriculum, analyzing the current semester in order to refute or affirm the observations obtained in the previous phase, seeking to solve existing problems in the academic lives of students from the SAI, when retained in some curricular components of the undergraduate program in IS. Quantitative variables shall be determined because of the subscribed veterans in disciplines process in order to collect data from these variables and statistical analysis of them, and then build the simulation model and scenarios for final analysis.

After the simulations are done, and the independent variables obtained from the simulation process model of subscribes veterans in disciplines. It will be possible to handle all the choice options for students and offer the best and analyze the consequences of this manipulation. After this phase of the research, a model optimized is offered to the mentoring of students in the SAI.

\section{REFERENCES}

Barradas, S., 2010, "Planejamento de Inclusão de Novos Equipamentos em uma Rede de Dslam: um Estudo de Simulação", dissertação de M. Sc. CEFET/RJ.

Engiel, P. , 2009, "Habilitando Processos De Prestação De Serviços À Participação E À Democracia - O Caso Da Escola De Informática Aplicada/Unirio", NP2Tec/UNIRIO.

Ferreira, J., Araujo, R., Baião F.A., 2009, “Comunicabilidade de Processos de Negócio para especificações de Sis", NP2Tec/UNIRIO.

Machado, D.V.C., 2006, "Inserção Da Simulação Computacional No Planejamento Hierárquico De Cadeias De Suprimento", dissertação de M.Sc. COPPE/UFRJ, Rio de Janeiro.

Magalhães, A., Cappelli, C., Baião, F., Santoro, F., Iendrike, H., Araujo, R. M., Nunes, V. T., 2007 "Uma Estratégia Para Gestão Integrada De Processos e Tecnologia da Informação Através da Modelagem de Processos de Negócio em Organizações”, CienteFico (Faculdade Rui Barbosa), v. I, p. 45-60.

Mareth, T.; Alves, T. e Borba, G., 2009, "Mapeamento De Processos E Simulação Como Procedimentos De Apoio À Gestão De Custos: Uma Aplicação Para O Processo De Registros E Matrículas Da Universidade De Cruz Alta", in: $9^{\circ}$ Congresso Usp De Controladoria E Contabilidade e $6^{\circ}$ Congresso USP de Iniciação Científica em Contabilidade, São Paulo. Exxito Editora.

Paim, R., Cardoso, V., Caulliraux, H. e Clemente, R. , 2009. Gestão de Processos: pensar, agir e aprender, Bookman, $1^{\text {a }}$ edição.

Saliby, E., 1999, "Tecnologia De Informação: Uso Da Simulação Para Obtenção De Melhorias Em Operações Logísticas".

Silva, Ana Paula Couto, 2006, "Métodos Computacionais para Modelos Markovianos com Recompensa", , Tese de doutorado, UFRJ;

Souza Jr, P.R., 2007, "Simulação Do Fluxo De Pacientes Nos Setores De Emergência Do Hospital Universitário Antônio Pedro", dissertação de M.Sc. COPPE/UFRJ, Rio de Janeiro.

Torres, I., Costa, M.A.B., 2006, "Introdução à

modelagem com Extend”, SIMUCAD/UFSC. 